\title{
SUPERAÇÃO DE DORMÊNCIA EM SEMENTES DE TRÊS ESPÉCIES DE Parkia spp. ${ }^{1}$
}

\author{
MARIA DA GLÓRIA GONÇALVES DE MELO2; MARIA SILVIA DE MENDONÇA ${ }^{3}$ \\ PATRÍCIA NAZÁRIO4; ANGELA MARIA DA SILVA MENDES 5 .
}

\begin{abstract}
RESUMO - O conhecimento dos processos germinativos de sementes com tegumentos resistentes, como ocorre em algumas espécies pertencentes à família Fabaceae, pode fornecer subsídios para a produção de mudas e recomposição de áreas degradadas. As sementes de Parkia apresentam germinação natural lenta e irregular, o que pode ser atribuído à impermeabilidade do tegumento. O trabalho foi desenvolvido com o objetivo de avaliar diferentes métodos de superação de dormência física das sementes de Parkia multijuga, P. velutina e $P$. panurensis. Foram utilizadas sementes coletadas na Base de Operações Geólogo Pedro de Moura (BOGPM), em Coari/AM, submetidas aos seguintes tratamentos: testemunha (T0), desponte (T1), desponte seguido da imersão em água por 8 horas (T2), escarificação mecânica do tegumento em esmeril elétrico (T3), escarificação mecânica do tegumento em esmeril elétrico seguido pela imersão em água por 8 horas (T4), punção com agulha quente (T5), punção com agulha quente seguido pela imersão em água por 8 horas (T6), imersão em ácido sulfúrico $\left(\mathrm{H}_{2} \mathrm{SO}_{4}\right)$ por 30 minutos (T7), imersão em ácido sulfúrico $\left(\mathrm{H}_{2} \mathrm{SO}_{4}\right)$ por 20 minutos (T8), imersão em ácido sulfúrico $\left(\mathrm{H}_{2} \mathrm{SO}_{4}\right)$ por 15 minutos (T9). As sementes de cada tratamento foram submetidas ao teste de germinação, avaliando-se a porcentagem de germinação, tempo médio de emergência de plântulas, índice de velocidade de emergência de plântulas e índice de sincronização. Em geral, todos os tratamentos pré-germinativos aplicados às sementes das três espécies, foram eficientes para aumentar a porcentagem de germinação em relação à testemunha. Os tratamentos de escarificação mecânica com esmeril elétrico na lateral da semente foram mais eficientes na superação da dormência de sementes de $P$. panurensis e $P$. multijuga, enquanto a escarificação química com ácido sulfúrico em maior tempo de imersão foi mais eficiente para as sementes de $P$. panurensis e $P$. velutina tanto para emergência de plântulas quanto para a formação de plântulas normais.
\end{abstract}

Termos para indexação: espécie florestal, tegumento impermeável, Parkia multijuga, Parkia velutina, Parkia panurensis.

\section{DORMANCY IN SEEDS OF THREE Parkia SPECIES.}

\begin{abstract}
Knowledge of the germinative processes of seeds with resistant coats, as have some Fabaceae species, may help in seedling production and the restoration of degraded areas. Parkia seeds have a naturally slow and irregular germination due to tegument impermeability.
\end{abstract}

${ }^{1}$ Submetido em 28/12/10. Aceito para publicação em 18/03/11. Parte da Tese de Doutorado da primeira autora.

${ }^{2}$ Eng. Florestal, Doutoranda do Programa de Pós-Graduação em Agronomia Tropical PPGAT/UFAM, Pesquisadora CTPETRO (PT2), Professora da Escola Superior de Tecnologia EST/UEA, Av. Darcyr Vargas 1200, Parque Dez, Caixa Postal 72, CEP: 69050020 - Manaus AM.Email: mgmelo@uea.edu.br

${ }^{3}$ Professora Titular da Faculdade de Ciências Agrárias da Universidade
Federal do Amazonas (FCA/UFAM), Av. Otavio Jordão Ramos, 3000, CEP: 69060-000 - Manaus - AM.

${ }^{4}$ Eng. Florestal, Doutoranda do Programa de Pós-Graduação em Ciências de Florestas Tropicais/INPA. Caixa Postal 478, CEP: 69011-970- Manaus - AM.

${ }^{5}$ Eng. Agrônoma, Pesquisadora do projeto CTPETRO (PT2), Av. Otavio Jordão Ramos, 3000, CEP: 69060-000 - Manaus - AM. 
This study aimed to evaluate different methods of overcoming physical dormancy in Parkia multijuga, P. velutina and P. panurensis seeds. Seeds were collected at the Pedro de Moura Operations Base (BOGPM), in Coari/AM, and subjected to the following treatments: control (T0), clipping (T1), clipping followed by immersion in water for 8 hours (T2), mechanical scarification of the tegument with an electric emery (T3), mechanical scarification of the tegument with an electric emery followed by immersion in water for 8 hours (T4), needle puncture in hot water (T5), needle puncture followed by immersion in hot water for 8 hours (T6 ), sulphuric acid immersion $\left(\mathrm{H}_{2} \mathrm{SO}_{4}\right)$ for 30 minutes (T7), sulphuric acid immersion $\left(\mathrm{H}_{2} \mathrm{SO}_{4}\right)$ for $20 \mathrm{~min}$ (T8), sulphuric acid immersion $\left(\mathrm{H}_{2} \mathrm{SO}_{4}\right)$ for 15 minutes (T9). The seeds of each treatment were submitted to germination tests to evaluate the percentage germination, average time of seedling emergence, seedling emergency speed index and synchronization rate. In general, all pre-germinative treatments on the seeds of the three species increased the percentage germination compared to the control. The mechanical scarification treatments with emery eletric on the side of the seed were more effective in overcoming the dormancy of $P$. panurensis and $P$. multijuga seeds while chemical scarification with sulphuric acid with a longer period of immersion was more effective for seeds of $P$. panurensis and $P$. velutina for both seedling emergence and normal seedling formation.

Index Terms: forest species, waterproof coat, Parkia multijuga, Parkia velutina, Parkia panurensis.

\section{INTRODUÇÃO}

Nas últimas décadas, a taxa de conversão de florestas tem sido particularmente elevada nos trópicos (Sarmento e Villela, 2010). Embora as taxas de desmatamento estejam diminuindo, ainda não é possível estabelecer uma tendência de estabilização ao longo do tempo.

A necessidade de conservação das florestas tropicais e a forte demanda social e científica pela conservação das florestas e recuperação de áreas ambientalmente degradadas são urgentes e se constitui em premissa básica. Esses fatores vêm, nos últimos anos, fortalecendo as políticas ambientais na promoção de um aumento de demanda de sementes de espécies nativas, que constituem insumo básico nos programas de recuperação ou conservação de ecossistemas, melhoramento florestal e biotecnologia (Sarmento e Villela, 2010).

Em contraste a esse fato, observa-se o avanço inexpressivo de estudos sobre as espécies florestais que compõem esses ecossistemas, do ponto de vista ecológico, biológico e tecnológico.

As espécies nativas ocupam importante e crescente espaço no mercado de sementes. No entanto, ainda existe uma lacuna para se formalizar as atividades de comercialização e controle de qualidade das sementes dessas espécies, tanto por falta de conhecimento do comportamento biológico de muitas espécies, como de padrões estabelecidos para a sua comercialização. Apesar de ser grande o número de espécies nativas comercializadas no Brasil para fins de recomposição florestal, e da inclusão de expressivo número de novas espécies nas Regras para Análise de Sementes (Brasil, 2009), esse número ainda é incipiente dada a diversidade de espécies em florestas tropicais.

A utilização de sementes é a maneira mais usual de propagação das espécies e também considerada mais fácil e econômica do que a propagação vegetativa e a micropropagação (Silveira et al., 2002). Porém, o sucesso na utilização de sementes depende de uma germinação rápida e uniforme, seguida por pronta emergência das plântulas, pois quanto mais tempo a plântula demorar a emergir e permanecer nos estádios iniciais de desenvolvimento, mais vulnerável estará exposta às condições adversas do ambiente (Martins et al., 2000).

Na maioria das espécies florestais, a dormência de sementes é um fato comum, sendo esta, em condições naturais, de grande valor por ser um mecanismo de 
sobrevivência da espécie. No entanto, passa a ser um problema quando as sementes são utilizadas para a produção de mudas em razão do longo tempo necessário para a germinação, ficando as mesmas sujeitas a condições adversas, com grandes possibilidades de ataques de fungos, o que acarreta em perdas (Borges et al.,1982).

O conhecimento dos processos germinativos, sobretudo daquelas sementes com tegumentos resistentes, como ocorre com a maioria das espécies pertencentes à família Fabaceae, pode fornecer subsídios para a produção de mudas e recomposição de áreas degradadas (PiñaRodrigues et al., 2007).

As sementes de Parkia apresentam dormência devido à impermeabilidade do tegumento, como já foi observado por Barbosa et al. (1984) e Fowler e Bianchetti (2000) e relatado por Oliveira et al. (2006), ou seja, as sementes são dotadas de dormência física, seguindo a classificação de Baskin e Baskin (1998), que dificulta a sua propagação.

Entre os tratamentos utilizados com sucesso para superação da dormência tegumentar de espécies florestais, destacam-se as escarificações mecânica e química. A aplicação e eficiência desses tratamentos dependem do grau de dormência, que é variável entre diferentes espécies, procedências e anos de coleta (Oliveira et al., 2003).

Os tratamentos visando a superação de dormência de sementes com tegumento impermeável à água apresentam vantagens e desvantagens, de modo que cada um deles deve ser estudado, levando-se em conta, também, o custo efetivo e a facilidade de execução. Diante do exposto, o trabalho foi desenvolvido com o objetivo avaliar diferentes métodos de superação da dormência física das sementes de Parkia multijuga, $P$. velutina e $P$. panurensis.

\section{MATERIAL E MÉTODOS}

As matrizes foram selecionadas em área de floresta natural, em terra-firme, ou seja, em área imune às inundações, caracterizada por apresentar espécies de maior porte (até $50 \mathrm{~m}$ ) (Noronha, 2003). Os frutos foram coletados de dez indivíduos por espécie, ao longo do rio Urucu e nas áreas de LUC (Leste do rio Urucu) na Base de Operações Geólogo Pedro de Moura (BOGPM), Coari/ AM, localizada a $623 \mathrm{~km}$ de Manaus, com as coordenadas geográficas $04^{\circ} 53^{\prime} \mathrm{S}$ e $65^{\circ} 11^{\prime} \mathrm{W}$.

A identificação do material botânico foi realizada no Herbário do Instituto Nacional de Pesquisas da Amazônia - INPA e as exsicatas preparadas e incluídas no acervo do
Herbário da Escola Superior de Tecnologia - EST, como documento taxonômico.

A extração das sementes foi feita de forma manual após imersão dos frutos em água por 72 horas. Em seguida as sementes foram lavadas em água corrente até a completa remoção do visgo por maceração em peneira sendo eliminadas as sementes, mal formadas, com injúrias mecânicas e/ou predadas por insetos.

As sementes, depois de beneficiadas, foram secadas em ambiente de laboratório por cinco dias e acondicionadas em sacos plásticos, etiquetados e armazenados por seis meses em câmara fria $\left(7^{\circ} \mathrm{C}\right)$, no Laboratório de Sementes da Escola Superior de Tecnologia, da Universidade do Estado do Amazonas.

Antes da instalação dos experimentos foi determinado o teor de água das sementes segundo Brasil (2009) com duas subamostras de $10 \mathrm{~g}$ de sementes inteiras para $P$. multijuga e 5 g para $P$. velutina e $P$. panurensis.

As sementes foram submetidas aos seguintes tratamentos pré-germinativos:

Testemunha (T0): sementes intactas, semeadas sem tratamento prévio.

Desponte (T1): com auxílio de um cortador de unha quadrado, o desponte da semente foi feito no lado oposto ao da emissão da raiz primária, deixando exposta uma pequena parte do cotilédone.

Desponte seguido da imersão em água por 8 horas (T2): seguindo o mesmo procedimento do desponte, as sementes foram imersas em água destilada em béquer de 1L, até a imersão total da amostra por 8 horas, em ambiente de laboratório $\left(25^{\circ} \mathrm{C}\right)$.

Escarificação mecânica do tegumento em esmeril elétrico (T3): as sementes foram friccionadas manualmente em esmeril elétrico, na região lateral de apenas um lado da semente até o desgaste do tegumento, evitando, contudo danificar o embrião.

Escarificação mecânica do tegumento em esmeril elétrico seguido pela imersão em água por 8 horas (T4): após a escarificação manual, as sementes foram imersas em água destilada em béquer de $1 \mathrm{~L}$, até a imersão total da amostra por 8 horas, em ambiente de laboratório $\left(25^{\circ} \mathrm{C}\right)$.

Punção com agulha quente (T5): em cada semente foi feita perfuração na região mediana do tegumento com auxílio de agulha quente, até que se visualizasse o cotilédone.

Punção com agulha quente seguido pela imersão em água por 8 horas (T6): após a punção no tegumento, as sementes foram imersas em água destilada em béquer de 
1L, até a imersão total da amostra por 8 horas, em ambiente de laboratório $\left(25^{\circ} \mathrm{C}\right)$.

Imersão em ácido sulfúrico $\left(\mathrm{H}_{2} \mathrm{SO}_{4}\right)$ por 30 minutos (T7): utilizando-se um béquer as sementes foram imersas em ácido sulfúrico ( $96 \%$ p.a) por trinta minutos.

Imersão em ácido sulfúrico $\left(\mathrm{H}_{2} \mathrm{SO}_{4}\right)$ por 20 minutos (T8): as sementes foram imersas em ácido sulfúrico $(96 \%$ p.a) por vinte minutos.

Imersão em ácido sulfúrico $\left(\mathrm{H}_{2} \mathrm{SO}_{4}\right)$ por 15 minutos (T9): as sementes foram imersas em ácido sulfúrico $(96 \%$ p.a) por quinze minutos.

As sementes tratadas com ácido sulfúrico foram lavadas em água corrente, à temperatura ambiente por aproximadamente cinco minutos com a finalidade de retirar o excesso de ácido e uniformizar as temperaturas.

As sementes de cada tratamento descrito anteriormente foram submetidas ao teste de germinação e a semeadura, feita em bandejas plásticas, perfuradas no fundo, contendo como substrato areia lavada, previamente peneirada a uma profundidade de duas vezes o diâmetro da semente permanecendo à temperatura ambiente em viveiro com $30 \%$ de sombreamento. A umidade do substrato foi mantida com irrigações diárias.

As características avaliadas foram: porcentagem de germinação, tempo médio de emergência (TME) (Edwards, 1934), índice de velocidade de emergência (IVE) (Maguire, 1962) e índice de sincronização (E) (Laboriau, 1983). Também foram avaliadas as sementes intactas e mortas no final do experimento. Consideraram-se como intactas, as sementes duras, que ao término do experimento não apresentavam sinais de deterioração ou embebição e como mortas, as sementes que se apresentavam amolecidas, atacadas por microorganismos e não apresentaram nem um sinal de início de germinação (Brasil, 2009). Para as sementes intactas, foi aplicado o teste de tetrazólio na concentração de $0,5 \%$ para $P$. panurensis e $P$. velutina conforme recomendado por Mendes et al., (2009) e a $1 \%$ para as sementes de P. multijuga por duas horas em estufa aos $40^{\circ} \mathrm{C}$, com o objetivo de verificar se as mesmas permaneciam viáveis.

Foi empregado o delineamento experimental inteiramente casualizado com 100 sementes por tratamento, distribuídas em quatro repetições de 25 sementes. Os dados foram submetidos a testes de normalidade (KolmogorovSmirvov e Shapiro-Wilk) e foi constatada a não normalidade na distribuição dos dados. Então, as médias dos tratamentos foram comparadas pelo teste de Kruskal-Wallis em 5\% de probabilidade. O software utilizado foi o ASSISTAT versão 7.5 beta (2010).

\section{RESULTADOS E DISCUSSÃO}

No início do experimento o teor de água das sementes foi de $11,0 \%$ para Parkia multijuga e Parkia velutina e $8,8 \%$ para Parkia panurensis. As contagens do número de sementes germinadas iniciaram-se aos 4 dias para $P$. panurensis e 5 dias para $P$. velutina e $P$. multijuga e estenderam-se até 152,340 e 451 dias respectivamente, utilizando-se como critério de germinação as emissões do epicótilo na superfície do substrato para $P$. multijuga e do hipocótilo para $P$. velutina e $P$. panurensis. Considerouse como plântula normal a expansão do eofilo com todas as estruturas essenciais da plântula em perfeito estádio de desenvolvimento.

Para P. multijuga a emergência do epicótilo foi superior nos tratamentos de escarificação mecânica do tegumento em esmeril elétrico (T3) e escarificação seguido de imersão em água por 8 horas (T4) (Figura 1A). Houve maior formação de plântula nos tratamentos de escarificação mecânica do tegumento (T3) e imersão em ácido sulfúrico por 30 minutos (T7) e todos os tratamentos diferiram da testemunha para os dois critérios avaliados.

De acordo com os resultados observados na Figura 2A, a emergência do hipocótilo das sementes de $P$. panurensis submetidas a qualquer um dos tratamentos testados diferiu da testemunha. Contudo, os tratamentos de escarificação mecânica do tegumento (T3) e imersão em ácido sulfúrico por 30 minutos (T7) apresentaram valores significativamente inferiores aos demais (Figura 2A). Pelo critério de formação de plântula normal todos os tratamentos diferiram da testemunha e as sementes submetidas aos tratamentos com ácido sulfúrico por 30 , 20 e 15 minutos (T7, T8 e T9 respectivamente) foram os que promoveram maiores valores, porém o tratamento $\mathrm{T} 7$ não diferiu dos tratamentos de escarificação mecânica do tegumento seguido de imersão em água por 8 horas (T4) e da punção com agulha quente seguido pela imersão em água por 8 horas (T6).

Para $P$. velutina a emergência dos tratamentos que foram submetidos a algum procedimento, foi superior à testemunha (Figura 3A). Os maiores valores de porcentagem de emergência foram obtidos nos tratamentos de desponte seguido de imersão em água por 6 horas (T2), escarificação mecânica do tegumento (T3), punção com agulha quente seguido pela imersão em água por 8 horas 
(T6) e imersão em ácido sulfúrico por 30 minutos (T7), sendo os três últimos significativamente iguais ao desponte

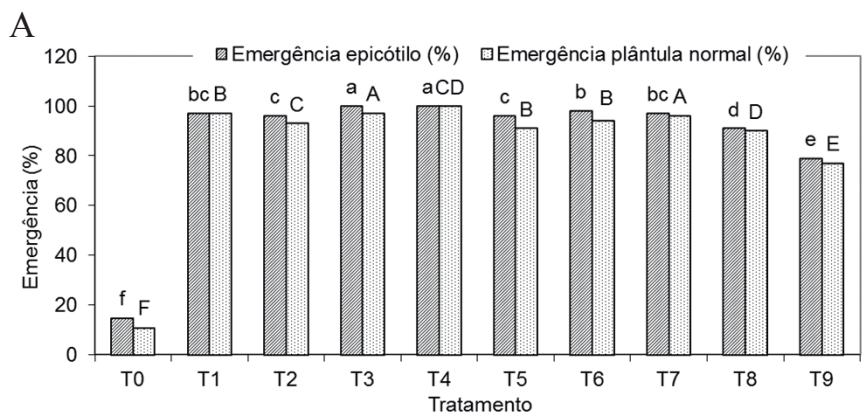

$\mathrm{C}$

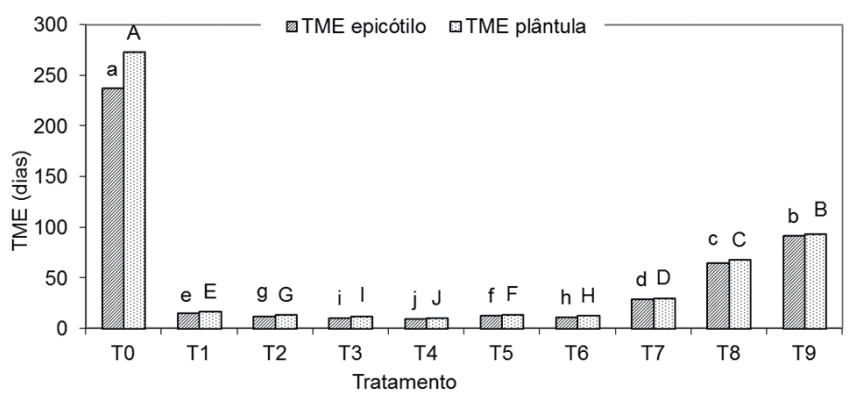

(T1) (Figura 3A). Quanto à formação de plântula normal, os tratamentos não diferiram entre si.

B

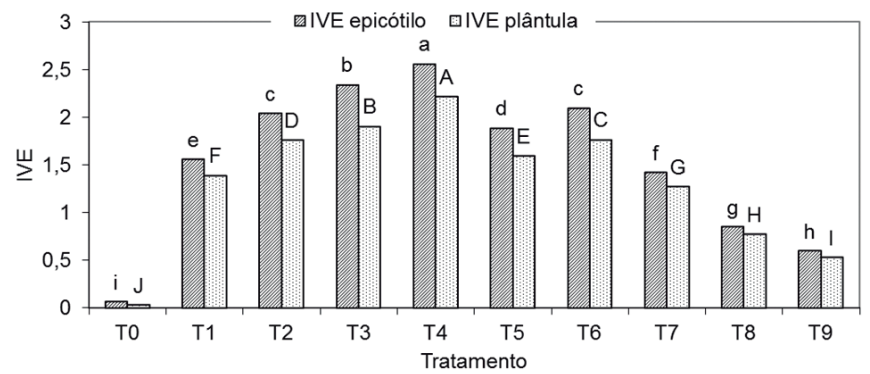

$\mathrm{D}$

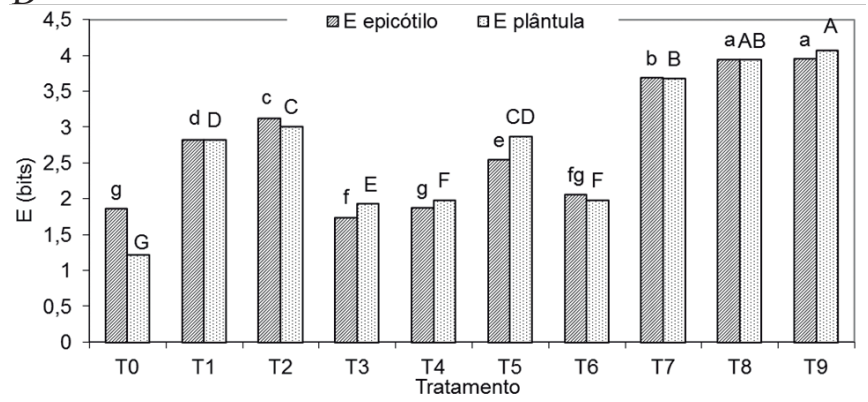

FIGURA 1. Emergência (A), índice de velocidade de emergência (IVE- B), tempo médio de emergência (TME- C), índice de sincronização (E- D) pelos critérios de emissão do hipocótilo e de formação de plântulas normais de Parkia multijuga.
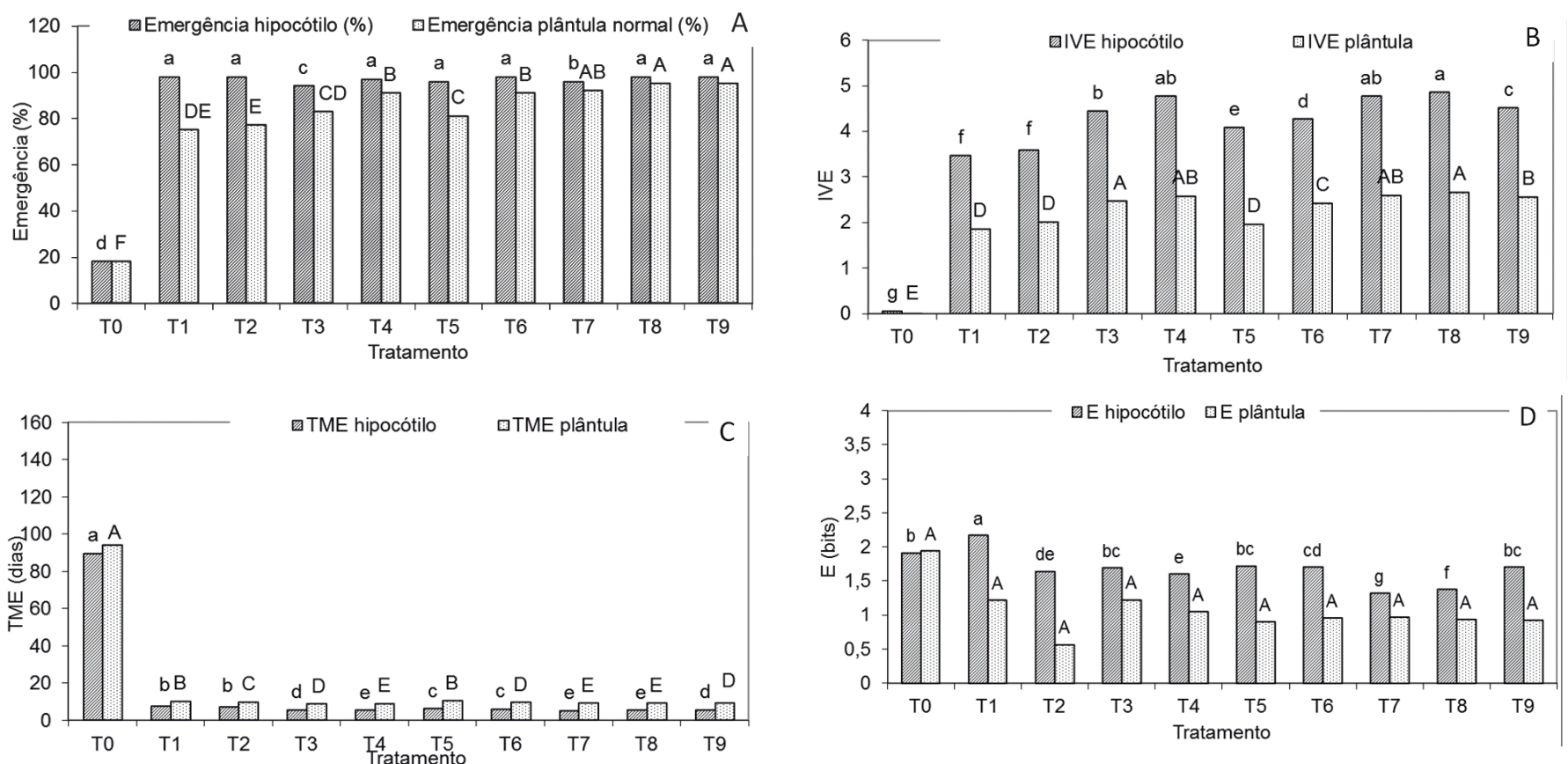

FIGURA 2. Emergência (A), índice de velocidade de emergência (IVE-B), tempo médio de emergência (TME-C), índice de sincronização (E-D) pelos critérios de emissão do hipocótilo e de formação de plântulas normais de Parkia panurensis. 

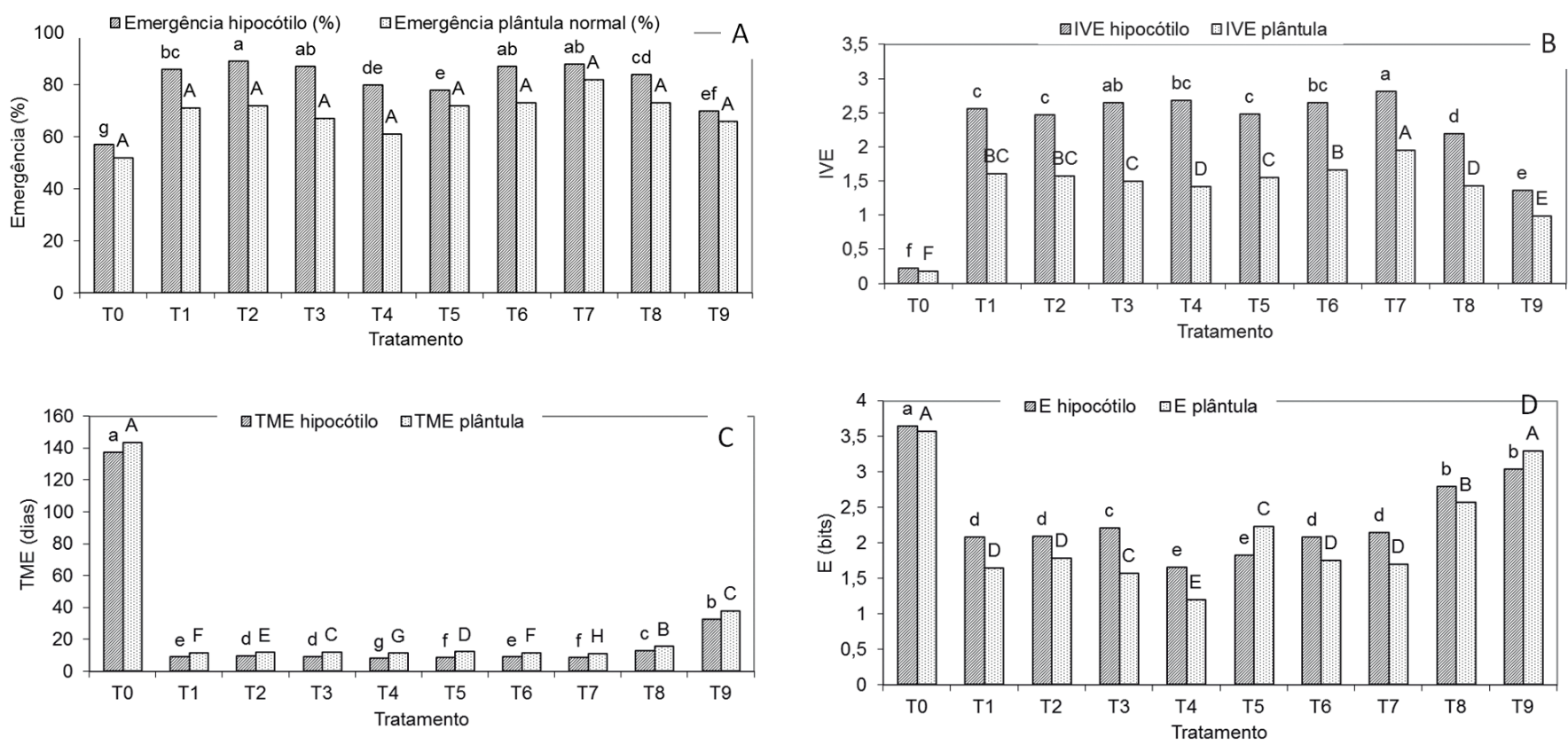

FIGURA 3. Emergência (A), índice de velocidade de emergência (IVE- B), tempo médio de emergência (TME- C), índice de sincronização (E- D) pelos critérios de emissão do hipocótilo e de formação de plântulas normais de Parkia velutina.

Para $P$. multijuga, o tratamento que resultou em maior índice de velocidade de emergência (IVE) e menor tempo médio de emergência (TME) foi o de escarificação seguido de imersão em água por 8 horas (T4), considerando-se a emissão de epicótilo e a formação de plântulas normais (Figura 1B-C). Todos os tratamentos proporcionaram maior IVE e menor TME comparados à testemunha, pelos dois critérios avaliados.

Os tratamentos de escarificação mecânica do tegumento seguido de imersão em água por 8 horas (T4) e com ácido sulfúrico por 30 e 20 minutos (T7 e T8) proporcionaram, para $P$. panurensis maiores índices de velocidade de emergência (IVE) e menores tempos médios de emergência (TME) do hipocótilo (Figura 2B-C). Os maiores índices de velocidade de emergência de plântulas normais ocorreram nos tratamentos T3, T4, T7 e T8 e os menores tempos médios para esse critério ocorreram nos tratamentos T4, T7 e T8. Para essas duas variáveis, nos dois critérios de avaliação, todos os tratamentos diferiram da testemunha.

Para $P$. velutina, os tratamentos que resultaram em maiores índices de velocidade de emergência (IVE) levando em consideração a emissão do hipocótilo foram o de escarificação mecânica do tegumento (T3) e imersão em ácido sulfúrico por 30 minutos (T7) e os menores tempos médios de emergência (TME) deram-se nos tratamentos de punção com agulha quente (T5) e imersão em ácido sulfúrico por 30 minutos (T7) (Figura 3B-C). Considerando-se a formação de plântulas normais, o maior IVE e menor TME ocorreram no tratamento T7. Todos os tratamentos proporcionaram maior IVE e menor TME comparados à testemunha.

Para as três espécies de Parkia estudadas, os tratamentos de superação da dormência física foram eficientes, o que pode ser observado, por diferirem da testemunha na promoção de uma emergência rápida e uniforme e no aumento do vigor, demonstrado pelo tempo médio de emergência (TME) e índice de velocidade de emergência (IVE). Em sementes de Sesbania sesban e Vigna oblongifolia (Fabaceae), Hu et al. (2009) verificaram que o principal local de entrada de água nas sementes após a quebra de dormência física pode variar de acordo com os tratamentos utilizados, o que pode determinar a velocidade da absorção de água, e subsequente germinação.

O desponte seguido ou não de embebição, embora não tenha aparecido como o tratamento mais eficiente para a superação da dormência, reduziu o tempo médio de emergência (TME) para as três espécies. Considerando 
o critério de emissão do epicótilo ou hipocótilo, para $P$. multijuga a redução foi de 238 para 13 dias (com embebição) e a 16 dias (sem embebição), para $P$. panurensis a redução foi de 89 para 7 dias e para $P$. velutina de 137 para 9 dias. Com esses tratamentos também houve redução no tempo médio de emergência (TME) para formação de plântulas normais de 273 para 14 a 18 dias para $P$. multijuga, de 94 para 10 dias para $P$. panurensis e de 143 para 11 a 12 dias para $P$. velutina.

Medeiros Filho et al. (2002) relataram que a escarificação mecânica provoca fissuras no tegumento, aumentando a permeabilidade e permitindo a embebição e, consequentemente, o início da germinação. Neste estudo, os tratamentos de escarificação mecânica com esmeril elétrico na lateral da semente seguidos ou não de embebição foram os mais eficientes na superação da dormência de $P$. multijuga e $P$. panurensis reduzindo o tempo de emergência de 238 para 10 dias e de 90 para 5 dias e formação de plântulas normais de 273 para 12 dias e 94 para 9 dias respectivamente. Para $P$. velutina este tratamento proporcionou redução de 136 para 8 dias na emissão do hipocótilo e de 143 para 11 dias na formação de plântulas normais.

Os tratamentos com punção com agulha quente reduziram o tempo médio de emergência (TME) com pequena vantagem para os que foram submetidos à embebição. Para $P$. multijuga o tempo médio de emergência (TME) para emissão do epicótilo foi reduzido para 12 a 13 dias, e para formação de plântulas normais para 14 a 15 dias. Para $P$. panurensis houve redução para 5 a 6 dias (com e sem embebição respectivamente) e para a formação de plântulas para 9 a 10 dias. Já em $P$. velutina o tempo médio de emergência (TME) foi reduzido para 8 a 9 dias na emissão do hipocótilo e de 11 a 12 dias na formação de plântulas normais.

Diversos autores ressaltam a eficiência da escarificação mecânica na superação da dormência física das sementes de leguminosas, como verificado nos trabalhos com sementes de Dimorphandra mollis (Hermansen et al., 2000), Operculina macrocarpa (Medeiros Filho et al., 2002), Bauhinia divaricata (Alves et al., 2004), Ormosia arborea (Lopes et al., 2004), Ormosia nitida (Lopes et al., 2006), Trifolium riograndense Burkart (Suñé e Franke, 2006), Senna siamea (Dutra et al., 2007), Enterolobium contortisiliquum (Alexandre et al., 2009) e de Parkia discolor (Pereira e Ferreira, 2010).

Os tratamentos com ácido sulfúrico foram os mais eficientes na superação da dormência de $P$. panurensis e $P$. velutina para os dois critérios avaliados com destaque para os maiores tempos de imersão. Em $P$. panurensis reduziu para 5 a 6 dias o tempo médio de emergência (TME) para emissão do hipocótilo e para 9 dias na formação de plântulas normais. Essa redução variou de 8 a 32 dias (hipocótilo), e de 10 a 37 dias (plântula) para $P$. velutina e de 29 a 92 dias (hipocótilo) e de 31 a 94 dias (plântula) para P. multijuga. Para as três espécies observa-se maior redução no tempo médio com maior tempo de imersão das sementes no ácido, sendo menos eficiente em sementes de P. multijuga.

Resultados semelhantes foram obtidos por Nascimento et al. (2009) com sementes de Parkia platycephala, em que o maior valor de índice de velocidade de emergência (IVE), foi obtido com sementes submetidas aos tratamentos de escarificação manual com lixa e imersão em ácido sulfúrico concentrado, por 15, 30 e 45 minutos. Entretanto, ao contrário dos resultados apresentados nesse trabalho, para sementes de P. multijuga, Bianchetti et al. (1998), recomendaram 16 minutos de imersão em ácido sulfúrico (96\% p.a) como suficientes para promover a superação da impermeabilidade do tegumento. A escarificação química com ácido sulfúrico concentrado por 20, 25 e 30 minutos foram mais eficientes na superação da dormência de Piptadenia moniliformis Benth. (Azeredo et al., 2010).

Para o critério emissão do epicótilo, em $P$. multijuga, os menores valores do índice de sincronização, foram atribuídos aos tratamentos testemunha (T0), escarificação seguido de imersão em água por 8 horas (T4) e punção com agulha quente seguido pela imersão em água por 8 horas (T6) e os maiores foram nos tratamentos de imersão em ácido sulfúrico por 20 minutos (T8) e por 15 minutos (T9) (Figura 1D). Para o critério formação de plântulas normais o tratamento testemunha (T0) apresentou o menor índice de sincronização e os maiores índices foram apresentados pelos tratamentos T8 e T9.

Para P. panurensis, pelo critério emissão do hipocótilo, o menor valor do índice de sincronização, que representa a germinação mais sincronizada, foi atribuído ao tratamento de imersão em ácido sulfúrico por 30 minutos (T7) e o maior, representando a menor sincronia, no tratamento com desponte (T1) e para o critério formação de plântulas normais não houve diferença entre os tratamentos testados (Figura 2D).

Em $P$. velutina pelo critério emissão do hipocótilo, os menores valores do índice de sincronização, foram atribuídos aos tratamentos de escarificação mecânica do tegumento seguido de imersão em água por 8 horas (T4) e punção com agulha quente (T5) e o maior foi no 
tratamento T0 (testemunha) (Figura 3D). Para o critério formação de plântulas normais o tratamento T4 apresentou o menor índice de sincronização e os maiores índices foram apresentados pelos tratamentos testemunha (T0) e imersão em ácido sulfúrico por 15 minutos (T9).

Em P. multijuga, no tratamento controle (T0), após 465 dias da semeadura, $6 \%$ das sementes morreram e $14 \%$ permaneciam viáveis pelo teste de tetrazólio (Tabela 1). No tratamento de imersão em ácido sulfúrico por 30 minutos (T7), 2\% morreram e $2 \%$ permaneceram viáveis no final da avaliação pelo teste de tetrazólio; no tratamento de imersão em ácido sulfúrico por 20 minutos (T8), $5 \%$ morreram e $4 \%$ permaneciam viáveis e no tratamento de imersão em ácido sulfúrico por 15 minutos (T9), $5 \%$ estavam mortas e $15 \%$ permaneciam viáveis. Nos demais tratamentos, todas as sementes não germinadas encontravamse mortas após término do experimento, considerando-se assim por apresentarem sinais nítidos de apodrecimento de acordo com (Brasil 2009).

TABELA 1. Condição das sementes de $P$. multijuga, $P$. panurensis e $P$. velutina remanescentes nos diferentes tratamentos após encerramento do experimento avaliadas pelo teste de tetrazólio.

\begin{tabular}{|c|c|c|c|c|c|c|c|c|c|c|}
\hline & \multicolumn{3}{|c|}{ Parkia multijuga } & \multicolumn{3}{|c|}{ Parkia panurensis } & \multicolumn{4}{|c|}{ Parkia velutina } \\
\hline & Viáveis & & Mortas & Viáveis & Mortas & & Viáveis & & Mortas & \\
\hline T0 & 80 & $\mathrm{a}$ & $5 \mathrm{~A}$ & $65 \mathrm{a}$ & 8 & & 21 & & 22 & \\
\hline $\mathrm{T} 1$ & 0 & $\mathrm{e}$ & $3 \mathrm{~A}$ & $0 \mathrm{~b}$ & 2 & $\mathrm{a}$ & 0 & c & 14 & $\mathrm{a}$ \\
\hline $\mathrm{T} 2$ & 0 & $\mathrm{e}$ & $4 \mathrm{~A}$ & $0 \mathrm{~b}$ & 2 & $\mathrm{a}$ & 0 & $\mathrm{c}$ & 11 & $\mathrm{a}$ \\
\hline $\mathrm{T} 3$ & 0 & $\mathrm{e}$ & $0 \mathrm{~A}$ & $0 \mathrm{~b}$ & 6 & $\mathrm{a}$ & 0 & $\mathrm{c}$ & 13 & $\mathrm{a}$ \\
\hline $\mathrm{T} 4$ & 0 & $\mathrm{e}$ & $0 \mathrm{~A}$ & $0 \mathrm{~b}$ & 3 & $\mathrm{a}$ & 0 & c & 20 & $\mathrm{a}$ \\
\hline T5 & 0 & $\mathrm{e}$ & $4 \mathrm{~A}$ & $0 \mathrm{~b}$ & 4 & $\mathrm{a}$ & 0 & $\mathrm{c}$ & 22 & $\mathrm{a}$ \\
\hline T6 & 0 & $\mathrm{e}$ & $2 \mathrm{~A}$ & $0 \mathrm{~b}$ & 2 & $\mathrm{a}$ & 0 & c & 13 & $\mathrm{a}$ \\
\hline $\mathrm{T} 7$ & 2 & $\mathrm{~d}$ & $2 \mathrm{~A}$ & $0 \mathrm{~b}$ & 4 & $\mathrm{a}$ & 0 & $\mathrm{c}$ & 12 & $\mathrm{a}$ \\
\hline $\mathrm{T} 8$ & 4 & $\mathrm{c}$ & $5 \mathrm{~A}$ & $0 \mathrm{~b}$ & 2 & $\mathrm{a}$ & 0 & $\mathrm{c}$ & 16 & $\mathrm{a}$ \\
\hline T9 & 15 & $\mathrm{~b}$ & $6 \mathrm{~A}$ & $0 \mathrm{~b}$ & 2 & $\mathrm{a}$ & 3 & $\mathrm{~b}$ & 27 & $\mathrm{a}$ \\
\hline
\end{tabular}

Letras iguais representam médias iguais pelo teste de Kruskal-Wallis no nível de 5\% de probabilidade.

O tratamento controle (T0) em P. panurensis, aos 165 dias da semeadura, apresentou $8 \%$ de sementes mortas e $27 \%$ viáveis pelo teste de tetrazólio (Tabela 1 ). Nos demais tratamentos, todas as sementes remanescentes, encontravam-se mortas ao término do experimento.

Em P. velutina, nos tratamentos T1, T2, T3, T4, T5, T6, T7 e T8, todas as sementes não germinadas, após 344 dias de semeadura encontravam-se mortas (Tabela 1). No tratamento controle (T0) após o encerramento do experimento, $22 \%$ das sementes estavam mortas e $21 \%$ apresentaram-se viáveis pelo teste de tetrazólio. No tratamento de imersão em ácido sulfúrico por 15 minutos (T9), 27\% morreram e $3 \%$ permaneciam viáveis pelo teste de tetrazólio.

As três espécies apresentaram sementes não germinadas no final da avaliação dos experimentos, onde se verificou pelo teste de tetrazólio, que a maioria das sementes sem tratamento para superação da dormência, permanecia viável, comprovando-se o alto grau de dormência das sementes, sem tratamento. Destacaramse com maior número de sementes intactas e viáveis $P$. multijuga, seguido de $P$. velutina e $P$. panurensis, apresentando diferenças no grau de impermeabilidade por espécie. Essa diferença pode ser atribuída à profundidade da linha do pleurograma no tegumento de cada espécie (menos impresso em $P$. multijuga e $P$. velutina e mais impresso em $P$. panurensis), macrosclereides e aos compostos fenólicos nas sementes. Gunn (1981) sugeriu que o pleurograma, de maneira similar ao hilo, pode também funcionar como uma válvula higroscópica, similar ao hilo das Papilionoideaes, o que foi confirmado no presente estudo.

Sert et al. (2009) comentaram que a impermeabilidade do tegumento de sementes de Cassia cathartica, espécie da mesma família de Parkia, se deve à cutícula, camada subcuticular e ou à porção cônica das macrosclereídes. 


\section{CONCLUSÕES}

Os tratamentos de escarificação mecânica com esmeril elétrico na lateral da semente reduzem o tempo de emergência, caracterizando eficiência na superação da dormência de sementes de Parkia panurensis e $P$. multijuga.

A escarificação química com ácido sulfúrico por 30 minutos é eficaz na superação da dormência das sementes de $P$. panurensis e $P$. velutina tanto para emergência quanto para formação de plântula normal.

O grau de impermeabilidade do tegumento das sementes apresenta variação entre as espécies estudadas devido às características morfoanatômicas do tegumento o que reflete nos resultados com as diferenças entre os tratamentos aplicados.

\section{REFERÊNCIAS}

ALEXANDRE, R.S.; GONÇALVES, F.G.; ROCHA, A.P.; ARRUDA, M.P. de.; LEMES, E. de Q.Tratamentos físicos e químicos na superação de dormência em sementes de Enterolobium contortisiliquum (Vell.) Morong. Revista Brasileira de Ciências Agrárias, v.4, n.2, p.156-159, 2009.

ALVES, A.U.; DORNELAS, C.S.M.; BRUNO, R.L.A.; ANDRADE, L.A.; ALVES, E.U. Superação da dormência em sementes de Bauhinia divaricata L. Acta Botânica Brasílica, v.18, n.4, p.871-879, 2004.

ASSISTAT. Assistência estatística: versão 7.5 beta 2010 . Disponível: htpp://www.assistat.com. Acesso em: 15 de nov. de 2010.

AZEREDO, G.A.; DE PAULA, R.C.; VELERI, S.V.; MORO, F.V. Superação de dormência de sementes de Piptadenia moniliformis Benth. Revista Brasileira de Sementes, v.32, n.2, p.49-58, 2010.

BARBOSA, A.P.; VASTANO JÚNIOR, B.; VARELA V.P. Tratamento pré-germinativo de sementes de espécies florestais tropicais II. Visgueiro (Parkia pendula Benth. Leguminoseae - Mimosoideae). Acta Amazonica v.4, p.280-288, 1984.

BASKIN, C.C.; BASKIN, J.M. Seed: Ecology, Biogeography, and Evolution of Dormancy and Germination. Academic Press, London, 1998. 666p.

BIANCHETTI, A.; TEIXEIRA, C.A.D.; MERTINS, E.P. Escarificação ácida para superar a dormência de sementes de pinho-cuiabano (Parkia multijuga Benth.). Comunicação
Técnica. Revista Brasileira de Sementes, v.20, n.31, p.215-218, 1998.

BORGES, E.E.L.; BORGES, R.C.G.; CANDIDO, J.F.; GOMES, J.M. Comparação de métodos de quebra de dormência em sementes de copaíba. Revista Brasileira de Sementes, v.4, n.1, p.9-12, 1982.

BRASIL. Ministério da Agricultura, Pecuária e Abastecimento. Regras para análise de sementes. Ministério da Agricultura, Pecuária e Abastecimento. Secretaria de Defesa Agropecuária. Brasília, DF: Mapa/ ACS, 2009. 395p.

DUTRA, A.S.; MEDEIROS-FILHO, S.; TEÓFILO, E.M.; DINIZ, F.O. Germinação de Sementes de Senna siamea (Lam.) H.S. Irwin E Barneby -Caesalpinoideae. Revista Brasileira de Sementes, v.29, n.1, p.160-164, 2007.

EDWARDS, T.I. Relations of germinating soy beans to temperature and length of incubation time. Plant Physiology, v.9, n.1, p.1-30, 1934.

FOWLER, J.A.P.; BIANCHETTI, A. Dormência em sementes florestais. Embrapa Florestas v.40, n 1-27, 2000 .

GUNN, C.R. Seed topography in the Fabaceae. Seed Science and Tecnology. Beltsville: Maryland, v.9, n.3, p.737-757, 1981.

HERMANSEN, L.A.; DURYEA M.L., WHITE T.L. Pretreatments to overcome seed coat dormancy in Dimorphandra mollis Benth. Seed Science and Technology, v.28, n.3, p.581-595, 2000.

HU, X.W.; WANG, Y.R.; WU, Y.P.; BASKIN, C.C. Role of the lens in controlling water uptake in seeds of two Fabaceae (Papilionoideae) species treated with sulphuric acid and hot water. Seed Science Research, n.19, p.73-80, 2009.

LABOURIAU, L.G. A germinação das sementes. Organização dos Estados Americanos. Programa Regional de Desenvolvimento Científico e Tecnológico. Série de Biologia. Monografia 24, 1983. 174p.

LOPES, J.C.; DIAS, P.C.; MACEDO, C.M.P. Tratamentos para superar a dormência de sementes de Ormosia arborea (Vell.) Harms. Brasil Florestal, n.80, p.25-35, 2004.

LOPES, J.C.; DIAS, P.C.; MACEDO, C.M.P. Tratamentos para acelerar a germinação e reduzir a deterioração das sementes de Ormosia nitida Vog. Revista Árvore, v.30, n.2, p.171-177, 2006.

MAGUIRE, J.D. Speed of germination-aid in selection and evaluation for seedling emergence and vigour, Crop 
Science, n.2, v.2, p.176-177, 1962.

MARTINS, C.C.; NAKAGAWA, J.; BOVI, M.L.A.; STANGUERLIM, H. Influência do peso das sementes de palmito-vermelho (Euterpe espiritosantensis Fernandes) na porcentagem e na velocidade de germinação. Revista Brasileira de Sementes, v.22, n.1, p.47-33, 2000.

MEDEIROS FILHO, S.; FRANÇA, E.A.; INNECCO, R. Germinação de sementes de Operculina macrocarpa (L.) Farwel e Operculina alata (Ham.) Urban. Revista Brasileira de Sementes, v.24, n.2, p.102-107, 2002.

MENDES, A.M.S.; BASTOS, A.A.; MELO, M.G.G. Padronização do teste de tetrazólio em sementes de Parkia velutina Benoist (Leguminosae - Mimosoideae). Revista Acta Amazônica, v.39, n.4, p.823-828, 2009.

NASCIMENTO, I.L.; ALVES, E.U.; BRUNO, R.L.A.; GONÇALVES, E.P.; COLARES, P.N. Q.; MEDIROS, M.S. Superação da dormência em sementes de faveira (Parkia platycephala Benth.). Revista Árvore, v.33, n.1, p.35-45, 2009.

NORONHA, M.C. Geoespaço: o espaço geográfico do Amazonas, editora Concorde, 2003. 256p.

OLIVEIRA, L.M.; DAVIDE, A.C.; CARVALHO, M.L.M. Avaliação de métodos para quebra da dormência e para a desinfestação de sementes de canafístula (Peltophorum dubium (Sprengel) Taubert). Revista Árvore, v.27, n.5, p.597-603, 2003.

OLIVEIRA, M.C.P.; FERRAZ, I.D.K.; OLIVEIRA, G.J. Dispersão e superação da dormência de sementes de Parkia pendula (Willd.) Walp. (visgueiro) na Amazônia Central, AM, Brasil. Hoehnea, v.33, n.4, p.485-493, 2006.

PEREIRA, S.A.; FERREIRA, S.A.N. Superação da dormência em sementes de visgueiro-do-igapó (Parkia discolor). Acta Amazonica, v.40, n.1, p.151-156, 2010.

PIÑA-RODRIGUES, F.C.M.; NOGUEIRA, E.S.; PEIXOTO, M.C. Estado da arte da pesquisa em tecnologia de sementes de espécies florestais da Mata Atlântica. In: PIÑA- RODRIGUES, F.C.M.; FREIRE, J.M.; LELES, P.S.S.; BREIER, T.B. (Org.). Parâmetros técnicos para produção de sementes florestais. Rede Mata Atlântica de Sementes Florestais. Seropédica: UFRRJ, 2007, p.1051141.

SARMENTO, M.B.; VILLELA, F.A. Sementes de espécies florestais nativas do Sul do Brasil. Informativo ABRATES, v.20, n.1,2, p.39-44, 2010.

SERT, M.A.; BONATO, C.M.; SOUZA, L.A. Germinação da Semente. In: SOUZA, L.A. Sementes e plântulas: germinação, estrutura e adaptação. Ponta Grossa, PR, 2009. 279 p.

SILVEIRA, M.A.M.; VILLELA, F.A.; TILLMANN, M.A.A. Maturação fisiológica de sementes de calêndula (Calendula officinalis L.). Revista Brasileira de Sementes, v.24, n.2, p.31-37, 2002.

SUÑÉ, A.D.; FRANKE, L.B. Superação de dormência e metodologias para testes de germinação em sementes de Trifolium riograndense Burkart e Desmanthus depressus Humb. Revista Brasileira de Sementes, v.28, n.3, p.2936, 2006. 